\title{
AOIR
}

Selected Papers of \#AoIR2020:

The $21^{\text {st }}$ Annual Conference of the

Association of Internet Researchers

Virtual Event / 27-31 October 2020

\section{LIVING WITH ROBOTS: AN ONTOLOGICAL LEAP?}

\author{
Kate K. Mays \\ Boston University \\ Yiming (Skylar) Lei \\ Michigan State University \\ James E. Katz \\ Boston University

\section{Introduction}

There is a vast research literature on human-robot interaction addressing how humans perceive of robots and their use. Artificial intelligence (AI) and robotics applications have proliferated primarily in the industrial sphere (Taipale, de Luca, Sarrica, \& Fortunati, 2015), and social scientific studies emphasized robots' functionality and appropriateness for certain roles, especially those related to work and most particularly to robots replacing humans' jobs. Notably, robot studies are often premised on negative prognostications, emphasizing how robots threaten livelihoods and are disruptive (Taipale \& Fortunati, 2018).

As $\mathrm{Al}$ and robot technologies advance, however, more positive possibilities arise for robots' social integration. Caretaking robots may fill gaps in end-of-life care; companion robots may ease loneliness; robot tutors may deliver personalized education; therapeutic robots may support autistic children's socialization (Leite, Martinho, Paiva, 2013; Giger, Picarra, Alver-Oliveira, Oliveira, \& Arriaga, 2019). While "social robots" (Breazeal, 2004) are not yet diffused in the mainstream, we can see an inkling of how they may be accepted in Al-enabled digital voice assistants such as Amazon's Alexa, which is treated as a friend/companion as much as a functional utility (Calvin, 2017).Thus, there may be both a greater demand for and acceptance of social robots. As Guzman (2020) points out, however, there is an ontological divide between humans and machines that will likely influence people's responses to and interactions with these emerging technologies.

Media equation theory (Reeves \& Nass, 1996) has established that people respond socially to robots that have human qualities. However, people can also attribute

Suggested Citation (APA): Mays, K. K., Lei, Y., Katz, J. E. (2020, October). Living with robots: An ontological leap? Paper presented at AoIR 2020: The 21 $1^{\text {st }}$ Annual Conference of the Association of Internet Researchers. Virtual Event: AoIR. Retrieved from http://spir.aoir.org. 
mechanical characteristics such as objectivity and randomness to technology when a "machine heuristic" is triggered (Sundar, 2008). Conversely, Mays, Katz, and Groshek (2020) have suggested a "human heuristic" may be triggered in interactions with automated technologies that focuses on the technology's lack of certain (human) qualities such as nuance, bias, and empathy, which may be desired during certain interactions (e.g., with customer service).

Technology has often been foregrounded as providing tools to ease humans' load or amplify their capabilities, and robots are often promoted as another technological tool to aid humans. Yet more than a tool, people can respond emotionally to such robotic technology (Vincent, 2015), and see them as a part of their lives and not simply an adjunct to accomplish a task (such as a household hammer). Robots' key functionalities - their interactivity and relative autonomy - make them closer to "living" and social entities than any technology than has come before. This ontological leap may create friction for people as they logically know and intend to treat robots as mere tools but begin confronting their social cues that prompt emotional and social responses. A logical next step would be to research and understand these possible dynamics and how people perceive robots as social and human-like entities.

\section{Method}

This study is a qualitative analysis of open-ended comments elicited in surveys about social perceptions of robots. Two online surveys were conducted through the professional survey company Qualtrics in May - June $2018(\mathrm{~N}=1,158)$ and February March $2019(\mathrm{~N}=2,254)$. Robot perceptions were measured through questions about cyberdystopianism, robot phobia, robot liking, robot-human likeness, and robot rights.

After answering the robot perception questions, respondents were given an optional open-text comment space. Off-topic and non-substantive remarks were removed, leaving 591 comments for analysis. A top-level analysis of the comments revealed five main themes about social life with robots. In some comments, more than one topic was addressed and when this occurred each component comment was coded independently.

\section{Results}

Robots as a tool/machine was the most common theme, appearing in $32.5 \%$ of comments $(n=192)$. Such comments urged that robots be considered as no more than lifeless machines and often emphasized that emotional capability was an essential criterion unique to humans. This theme overlapped most with the topic of human-robot relationships ( $26.9 \%$ of comments, $n=159)$. Respondents imagined the consequences of human-robot interaction, and held a relatively open-minded or even positive attitude about a future with robots, though some held that the ontological boundary of robot as tool was necessary for such optimism.

To that end, the social adjustment theme $(19.0 \%, n=112)$ spoke of robots' potential jobs, life roles, social status, and subsequent potential threats to humans with such an integration. Some clearly rejected any kind of social integration, while others were 
intermediate, conditioning it on performing menial tasks and/or occupying an inferior status. Robot rights also appeared as a theme $(10.7 \%, n=63$, likely elicited by answering the survey's "robot rights" measure). Respondents expressed feeling ridiculous about even considering the notion of rights for robots, though some acknowledged that if robots should one day have emotions, they should be allowed some or equivalent rights. Finally, robots' aliveness/appearance was discussed in $10.0 \%$ of comments $(n=65)$, and were largely negative in that they felt "creeped out" or scared of robots as living entities.

These findings show support for claims (e.g., Guzman, 2020) that human-robot ontology is an important consideration for robots' social acceptance and integration. Al-supported robotic technology presents great promise; however, its advancement challenges the ontological divide that has implications not only for human-machine interaction but also for self-identity and ultimately human-human relations. In terms of suggestions, these dynamics should be explored in tandem with ways to improve human-machine communication and considered from usability and design standpoints.

\section{References}

Breazeal, C. (2004). Designing Sociable Robots. Cambridge, MA: MIT Press.

Calvin, A.P. (2017, March 30). Can Amazon's Alexa be your friend? Digg.com. Retrieved from http://digg.com/2017/amazon-alexa-is-not-your-friend

Giger, Piçarra, Alves-Oliveira, Oliveira, \& Arriaga. (2019). Humanization of robots: Is it really such a good idea? Human Behavior and Emerging Technologies, 1(2), 111-123

Guzman, A. L. (2020). Ontological boundaries between humans and computers and the implications for human-machine communication. Human-Machine Communication, 1(1), 3.

Leite, I., Martinho, C., \& Paiva, A. (2013). Social robots for long-term interaction: a survey. International Journal of Social Robotics, 5(2), 291-308.

Mays, K., Katz, J., \& Groshek, J. (2020, January). Mediated communication and customer service experiences: Psychological and demographic predictors of user evaluations in the United States. In Proceedings of the 53rd Hawaii International Conference on System Sciences.

Reeves, B., \& Nass, C. I. (1996). The Media Equation: How People Treat Computers, Television, and New Media like Real People and Places. Cambridge, UK: Cambridge University Press.

Sundar, S.S. (2008). The MAIN Model: A heuristic approach to understanding technology effects on credibility. Digital Media, youth, and credibility. In M. J. Metzger \& A.J. Flanagin (Eds.). The John D. and Catherine T. MacArthur Foundation Series on Digital Media and Learning (73-100). Cambridge, MA: The MIT Press. 
Taipale, S., de Luca, F., Sarrica, M., Fortunati, L. (2015). Robot shift from industrial production to social reproduction. In J. Vincent et al. (eds.), Social Robots from a Human Perspective. Cham: Springer International Publishing, Switzerland, 11-24.

Taipale, S. \& Fortunati, L. (2018). Communicating with machines: Robots as the next new media. In A. Guzman (ed.), Human-Machine Communication: Rethinking Communication, Technology, and Ourselves. (pp.201-220). New York: Peter Lang.

Vincent, J. (2015). The mobile phone: An emotionalized social robot. In J. Vincent, S. Taipale, B. Sapio, G. Lugano, \& L. Fortunati (Eds.), Social robots from a human perspective. (pp. 105-115). Cham, Switzerland: Springer International. 